\title{
A closer look at multiple-clone Plasmodium vivax infections: detection methods, prevalence and consequences
}

\author{
Tatiana Havryliuk ${ }^{1,2}$, Marcelo U Ferreira ${ }^{1 /+}$ \\ 1'Departamento de Parasitologia, Instituto de Ciências Biomédicas, Universidade de São Paulo, Av. Prof. Lineu Prestes 1374, 05508-900 \\ São Paulo, SP, Brasil ${ }^{2}$ Mount Sinai School of Medicine, New York, NY, USA
}

The naturally occurring clonal diversity among field isolates of the major human malaria parasite Plasmodium vivax remained unexplored until the early 1990s, when improved molecular methods allowed the use of blood samples obtained directly from patients, without prior in vitro culture, for genotyping purposes. Here we briefly review the molecular strategies currently used to detect genetically distinct clones in patient-derived P. vivax samples, present evidence that multiple-clone P. vivax infections are commonly detected in areas with different levels of malaria transmission and discuss possible evolutionary and epidemiological consequences of the competition between genetically distinct clones in natural human infections. We suggest that, when two or more genetically distinct clones are present in the same host, intra-host competition for limited resources may select for P. vivax traits that represent major public health challenges, such as increased virulence, increased transmissibility and antimalarial drug resistance.

Key words: malaria - Plasmodium vivax - microsatellites - multiple-clone infections - within-host competition - virulence

Plasmodium vivax is the most widespread human malaria parasite, causing an estimated 132-391 million episodes of disease each year (Hay et al. 2004), with 2.6 billion people at risk of infection worldwide (Guerra et al. 2006). Outside of Africa, P. vivax is the main cause of malaria morbidity, with an enormous, but largely overlooked, public health burden. Historically, $P$. vivax malaria has received little attention and limited funds for research and control, since it usually produces less severe symptoms than Plasmodium falciparum (Price et al. 2007). With the recent emergence of drug resistance (Baird 2004) and increased virulence (Rogerson $\&$ Carter 2008) among P. vivax strains, considerable research efforts devoted to the study of this parasite are now underway.

In vitro cloning protocols developed in the early 1980s allowed for the phenotypic characterization of genetically diverse lineages of $P$. falciparum co-infecting the same host (Rosario 1981). The same strategy could not, however, be immediately applied to other human malaria parasites due to the lack of practical methods for their long-term propagation and cloning in vitro (Udomsangpetch et al. 2008). The clonal diversity of natural $P$. vivax infections in humans remained unexplored until the early 1990s. At that time, advances in molecular methods - particularly with the implementation of poly-

Financial support: CNPq, Mount Sinai School of Medicine

+ Corresponding author: muferrei@usp.br

Received 6 August 2008

Accepted 11 December 2008 merase chain reaction (PCR)-based protocols to amplify parasite DNA - allowed for the genotyping of malaria parasite samples obtained directly from patient blood without a preceding in vitro culture step (Kimura et al. 1990). Over the following years, these techniques revealed that multiple-clone (also known as mixed-strain) $P$. vivax infections are very common in areas with quite variable levels of malaria transmission.

Here, we briefly review the methods currently used to investigate the clonal diversity of patient-derived $P$. vivax samples, present available estimates for the prevalence of multiple-clone $P$. vivax infections worldwide and discuss possible evolutionary and epidemiological consequences of the co-occurrence of genetically distinct clones of this major parasite in natural human infections.

\section{Varying detection methods}

The earliest attempts to investigate the genetic diversity of $P$. vivax isolates relied on the use of monoclonal antibodies or isoenzymes to characterize phenotypes (Udagama et al. 1987, 1990, Joshi et al. 1989). This approach could only be applied to blood samples with relatively high parasitaemias. Over the last two decades, the detection of multiple-clone infections has improved substantially with the use of a greater number of polymorphic molecular markers. The specific PCR-based amplification of parasite DNA, alone or accompanied by DNA sequencing or restriction analysis, made possible the sensitive detection of diversity at the genome level while bypassing the requirement for in vitro propagation of parasites (Cui et al. 2003a). More recently, the use of high-fidelity multiple displacement amplification technology (Dean et al. 2002) for whole-genome amplification of malaria parasite DNA prior to PCR (Karunaweera et al. 2007, 2008, Wang et al. unpublished observations) has further extended the applicability of molecular 
methods to samples containing limited amounts of DNA template, thus allowing for more comprehensive largescale genotyping studies of $P$. vivax.

The first molecular markers used for $P$. vivax studies were orthologues of the ones already described in $P$. falciparum. The recent completion of the sequence of the $P$. vivax genome (Carlton et al. 2008) has, however, opened the doors for discovery of novel single-nucleotide polymorphisms (Feng et al. 2003) and highly polymorphic microsatellite markers (Inwong et al. 2006, Karunaweera et al. 2007). Earlier molecular studies of $P$. vivax diversity focused on antigen-coding single-copy genes, such as merozoite surface protein-1 (MSP-1), merozoite sur-

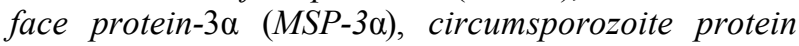
$(C S P)$ and apical membrane antigen-1. Additional focus was placed on markers of antimalarial drug resistance, such as mutations in the gene coding for dihydrofolate reductase, due to their importance for vaccine development and drug resistance surveillance. The patterns of diversity revealed by these markers reflect the combined effects of the parasite's population history and selective constraints imposed by the host's immunity or antimalarial drug use (Escalante et al. 2004). Thus, these marker types are not very informative about the population structure of this species as a whole.

The current markers of choice for large-scale population genetic studies of eukaryotes are the highly polymorphic short (1-6 bp long) tandem repeats known as microsatellites (Schlotterer 1998). Microsatellite markers are not as abundant across the genome of $P$. vivax (Feng et al. 2003, Carlton et al. 2008) as they are in that of P. falciparum (Joy et al. 2004). In addition, it was initially suggested that there was little polymorphic variation at these microsatellites among worldwide isolates (Leclerc et al. 2004). However, highly variable microsatellite markers have been more recently described and used in population-level studies of genetic variation in this species (Gomez et al. 2003, Imwong et al. 2006, 2007a, b, Ferreira et al. 2007, Karunaweera et al. 2007, 2008, Carlton et al. 2008).

Microsatellite repeat variation is usually free of strong selective constraints (Joy et al. 2004). Microsatellites can also be effectively used to detect genetically distinct clones in patients, although some challenges remain in the interpretation of the genotyping results. For example, minor alleles (those corresponding to less abundant clones) can theoretically be differentiated from the predominant allele by measuring the relative abundance of the respective PCR amplicons, which are labelled with fluorescent dyes, following electrophoretic separation with automated DNA sequencers. This strategy permits classification of the predominant multilocus haplotype in clone mixtures, based on the unique combination of the most abundant alleles at each locus analyzed (Anderson et al. 1999). We recently used mixtures of genomic DNA from two genetically distinct $P$. vivax isolates from Brazil to investigate how accurately microsatellite genotyping describes the overall genetic diversity and characterizes multilocus haplotypes in multipleclone infections. We found varying PCR amplification

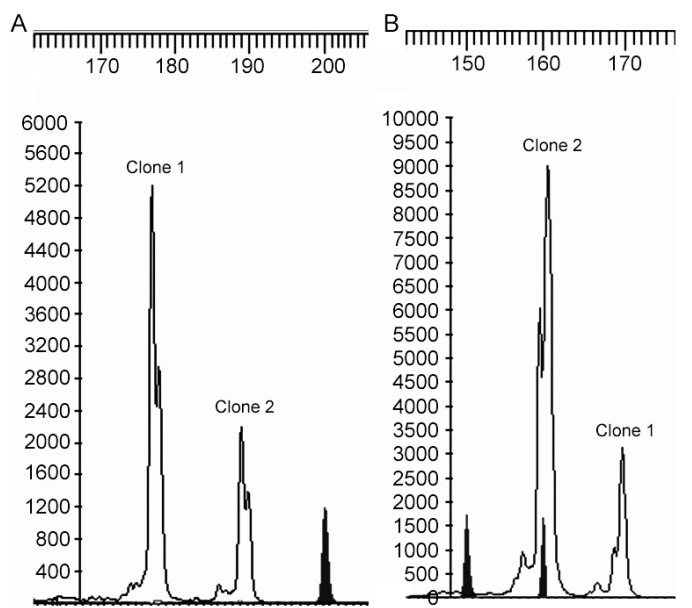

Fig. 1: electropherograms for two microsatellite markers, amplified from the same mixture of genomic DNA from two Plasmodium vivax clones (here identified as clone 1 and clone 2). Y-axis shows arbitrary fluorescence units; notice varying fluorescence scales for each microsatellite. X-axis represents DNA fragment size in bp and filled peaks correspond to the Genescan 500HD Rox size standard used. For microsatellite MS5 (A), the peak corresponding to the allele found in clone 1 is higher than that of clone 2 (peak height ratio, 2.4:1). An opposite pattern is found for microsatellite $M S 9$ (B), for which the allele corresponding to clone 2 has been preferentially amplified (peak height ratio, 2.9:1). However, these markers were amplified from the same mixture of clones, with a constant proportion of genomic DNA from clones 1 and 2 .

efficiencies of microsatellite alleles (Fig. 1), suggesting that amplification biases may lead to the inaccurate assignment of predominant haplotypes in multiple-clone P. vivax infections (Havryliuk et al. 2008).

In addition, minor alleles may be confused with artefacts such as stutter peaks or unspecific PCR amplification products (Fig. 2). Stutter peaks result from DNA strand slippage during PCR at intervals corresponding to nucleotide repeat sizes (de Valk et al. 2007). A minimum value of either one-third (Anderson et al. 2000, Imwong et al. 2007a, Karunaweera et al. 2008) or one-fourth (Anderson et al. 1999) of the predominant allele peak height has been used as a cut-off to differentiate minor alleles from stutter or unspecific peaks, but the sensitivity and specificity of these criteria remain undetermined (Greenhouse et al. 2006, Havryliuk et al. 2008).

Although most studies consider an infection to contain multiple clones if more than one allele is found for at least one microsatellite locus, others follow more stringent requirements. These strict criteria have been suggested because the detection of two or more alleles at some microsatellite loci may be a result of any of the artefacts mentioned above, which could potentially lead to an overestimation of the proportion of multiple-clone infections. Imwong et al. (2007a) observed great drops in multiple-clone infection detection rates in $P$. vivax isolates from South America and Asia as the requirement for the number of microsatellite loci with multiple alleles 

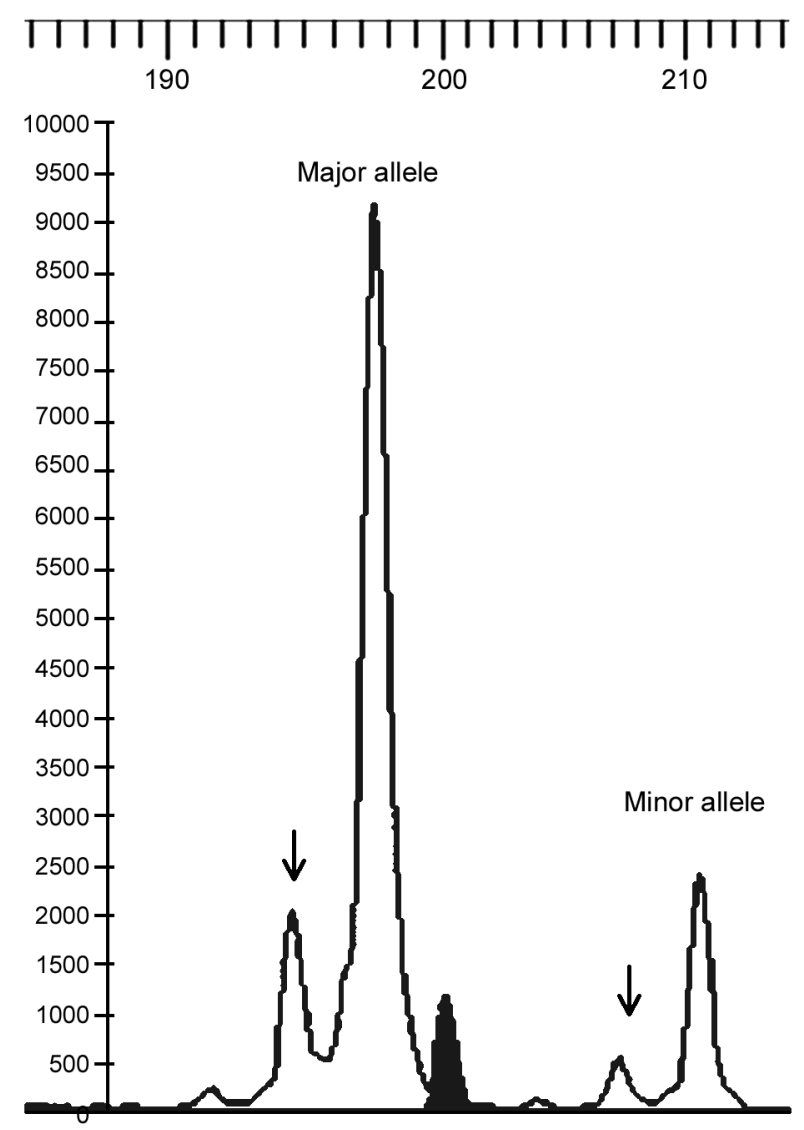

Fig. 2: electropherogram for microsatellite MS4 amplified from a mixture of genomic DNA from two Plasmocium vivax clones. Y-axis shows arbitrary fluorescence units and $\mathrm{x}$-axis represents DNA fragment size in bp. Filled peaks correspond to the Genescan 500HD Rox size standard used. Note that stutter peaks (arrows) are found for both the major allele (clone 1) and the minor allele (clone 2). when the two markers were combined. A similar trend was observed in the analysis of 141 isolates from India described by Kim et al. (2006).

With the growing use of microsatellite genotyping, it becomes more important to define an optimal range for the number of markers that would accurately estimate multiple-clone infection rates without incurring unnecessary cost. As a first attempt to determine the minimum number of microsatellite markers required to score all multiple-clone infections in a population, we used a dataset comprising 39 multiple-clone infections found in 77 P. vivax isolates from Brazil (Ferreira et al. 2007). We first ranked the 14 microsatellite markers analyzed according to their discriminatory ability, which was estimated by calculating their virtual heterozygosity $\left(H_{\mathrm{E}}\right)$ values. Virtual heterozygosity is defined as $H_{\mathrm{E}}=[\mathrm{n} /(\mathrm{n}$ -1)][1- $\left.\sum p_{i}^{2}\right]$, where $\mathrm{n}$ is the number of isolates analyzed and $p_{i}$ is the frequency of the $i$-th allele in the population. Values range between 0-1. Virtual heterozygosity, in this context, gives the average probability that a pair of alleles randomly obtained from the population is different. It is synonymous with the Simpson's index of diversity, which has previously been suggested by Hunter and Gaston (1988) as a means to evaluate the discriminatory ability of genotyping systems for bacterial strains. We then used the marker with the highest $H_{\mathrm{E}}$ to estimate the percent of multiple-clone infections detected $(28 \%$ of the total multiple-clone infections). The rest of the markers, in order of decreasing $H_{\mathrm{E}}$ values, were added one at time to our analysis. As shown in Fig. 3, we found that all of the multiple-clone infections could be detected with the use of only 11 markers and that $90 \%$ could be detected with nine markers. This suggested that an even smaller number of markers could probably be used in the future genotyping studies of multiple-clone infections. Further grew. Similar results were recently found in an extensive study of microsatellite variation of $P$. vivax isolates from Mexico (Joy et al. 2008). Nevertheless, detection of parasite clones co-infecting the same host that differ at only one of the 10 or even 20 microsatellite loci analyzed is not necessarily artificial. A careful analysis of P. falciparum clones obtained from patients naturally infected in areas of very low transmission revealed that clone mixtures usually comprise genetically related parasites. A possible explanation for this is that they descended from the same parental clones, which had recombined during the sexual phase of the parasite's life cycle in the mosquito vector (Druilhe et al. 1998). If this is also the case for $P$. vivax malaria, the use of more stringent criteria might grossly underestimate the clonal diversity of natural infections.

Augmenting the number of markers increases the possibility of detecting multiple clones. For example, in 90 P. vivax isolates from Thailand, Cui et al. (2003b) found a multiple-clone infection rate of $25.6 \%$ using the CSP gene alone, $19.3 \%$ using $M S P-3 \alpha$ alone and $35.6 \%$

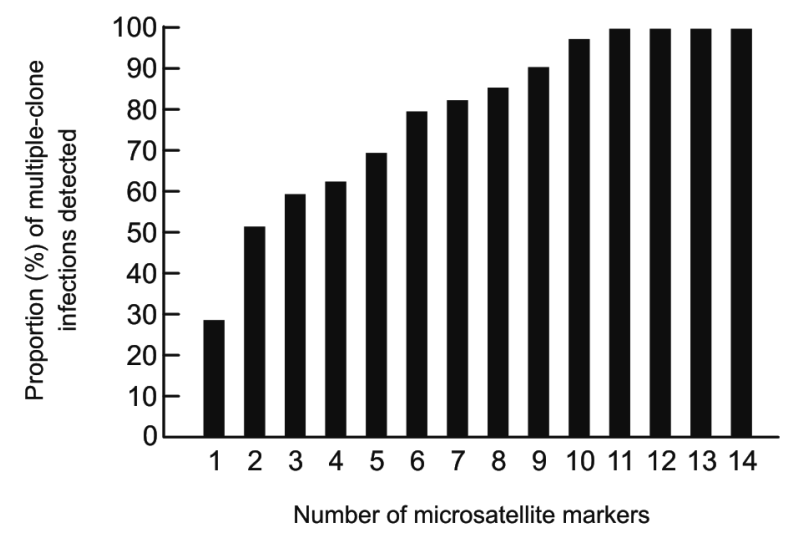

Fig. 3: relationship between the number of microsatellite markers typed and percent of multiple-clone infections detected. The sample set comprised 39 multiple-clone infections detected in 77 Plasmodium vivax isolates from state of Acre, Brazil (Ferreira et al. 2007). The markers were added one by one in decreasing order of virtual heterozygosity $\left(H_{\mathrm{E}}\right)$ values. By combining 11 markers (MS16, MS8, $M S 20, M S 9, M S 4, M S 5, M S 10, M S 1, M S 6, M S 15$, and $M S 7)$ all multiple-clone infections were detected. 
estimates for the optimal number of microsatellite markers are required for populations in other geographic areas, given that the $H_{\mathrm{E}}$ values of markers might vary.

Numerous molecular markers are finally becoming available for the comprehensive description of $P$. vivax diversity. However, this multitude of methods also compromises the ability to compare multiple-clone infection rates across different studies. The application of standardized genotyping protocols in the future promises to overcome this setback.

\section{Prevalence and consequences of multiple-clone $P$. vivax infections}

The use of different molecular markers led to the detection of widely variable proportions of multiple-clone P. vivax infections worldwide (Table) (Joshi et al. 2008). In general, multilocus analysis, such as microsatellite genotyping, detected greater numbers of multiple-clone infections when compared to single-locus analysis. The extensive clonal diversity of $P$. vivax infections in areas with relatively low malaria transmission, such as in Brazil and Colombia, is particularly surprising (Ferreira et al. 2007, Imwong et al. 2007b). The only published comparison of microsatellite diversity in two human malaria parasite species co-circulating in the same area suggests that $P$. vivax infections comprise multiple clones (12 multiple-clone infections among 25 isolates typed) more often than $P$. falciparum infections (6 multiple-clone infections among 34 isolates typed) in rural Amazonia (Ferreira et al. 2007). Parasite relapses provide a biologic basis for increased clonal diversity in $P$. vivax isolates, especially when compared to non-relapsing species such as $P$. falciparum. The dormant liver stages known as hypnozoites extend the duration of $P$. vivax carriage in human hosts to weeks or months. While infected with hypnozoites, the host may become superinfected with a new strain. Thus, when the hypnozoites awaken, two genetically distinct strains may be present and detectable in the bloodstream.

Competition between co-infecting parasite clones for limited resources within a host is a major factor in the evolution of phenotypes such as virulence, transmissibility and drug resistance (Mackinnon \& Read 2004). A series of elegant experiments with mice co-infected with different strains of Plasmodium chabaudi revealed that competition favours strains with higher virulence (de Roode et al. 2005, Bell et al. 2006), greater gametocyte production and increased transmissibility to mosquitoes (Taylor et al. 1997, de Roode et al. 2005). Early gametogenesis allows $P$. vivax transmission to occur before symptoms appear and, thus, before drug treatment is started. This can lead to increased gametocyte production in multiple-clone infections, which may have a major public health impact even in those areas where early diagnosis and treatment of malaria can be achieved (Sattabongkot et al. 2004). In addition, when clone mixtures are comprised of drug-resistant and drug-sensitive $P$. chabaudi strains, the removal of susceptible clones by drug therapy promoted the expansion of resistant parasites to a level far beyond that achieved when a competitor had never been present (Wargo et al. 2007). Therefore, these experimental results imply that within-host competition may accelerate the spread of drug resistance in malaria parasites.

Whether or not similar effects occur in human co-infections with genetically diverse $P$. vivax strains remains unknown (Mackinnon \& Read 2004). The increasing virulence of $P$. vivax strains, as demonstrated by numer-

TABLE

Proportions of isolates with multiple clones detected with different molecular markers in Plasmodium vivax populations

\begin{tabular}{|c|c|c|c|}
\hline Markers & $\begin{array}{c}\text { Papua New Guinea } \\
\%(n)\end{array}$ & $\begin{array}{l}\text { Asia } \\
\%(n)\end{array}$ & $\begin{array}{l}\text { Americas } \\
\%(\mathrm{n})\end{array}$ \\
\hline Microsatellites & & $\begin{array}{l}\text { Thailand: } 63.6(88)^{i}, 52.8(36)^{j} \\
\text { India: } 47.8(67)^{i}, 10.5(38)^{j} \\
\text { Sri Lanka: } 9.1(22)^{m}, 60.0(20)^{m} \\
\text { Laos: } 58.6(71)^{i} \\
\text { Myanmar: } 65.3(75)^{i}\end{array}$ & $\begin{array}{l}\text { Brazil: } 48.0(25)^{k}, 49.0(49)^{k} \\
\text { Colombia: } 38.6(43)^{i} \\
\text { Mexico: } 15.8(234)^{n}\end{array}$ \\
\hline$C S P$ & $32.5(40)^{b}$ & $\begin{array}{l}\text { Thailand: } 25.6(90)^{e} \\
\text { India: } 1.3(151)^{g}\end{array}$ & Guyana: $39.3(61)^{f}$ \\
\hline$M S P-1$ & $37.5(40)^{b}$ & $\begin{array}{l}\text { Thailand: } 7.1(14)^{d} \\
\text { India: } 0.7(151)^{g}\end{array}$ & Brazil: $47.8(23)^{a}$ \\
\hline$G A M-1$ & & India: $13.1(252)^{h}$ & \\
\hline$M S P 3 \alpha$ & $22.7(22)^{c}$ & $\begin{array}{l}\text { Thailand: } 19.3(90)^{e} \\
\text { India: } 8.6(151)^{g} \\
\text { Sri Lanka: } 12.8(39)^{l}\end{array}$ & \\
\hline
\end{tabular}

$a$ : Porto et al. $1992 ; b$ : Kolakovich et al. 1996; $c$ : Bruce et al. 1999; $d$ : Putaporntip et al. 2000; $e$ : Cui et al. 2003; $f$ : Bonilla et al. 2006; $g$ : Kim et al. 2006; $h$ : Prajapati et al. 2006; $i$ : Inwong et al. 2007a; $j$ : Inwong et al. 2007b; $k$ : Ferreira et al. 2007; $l$ : Gunasekera et al. 2007; $m$ : Karunaweera et al. 2007; $n$ : Joy et al. 2008; CSP: circumsporozoite protein; GAM1: gametocyte antigen 1; MSP1: merozoite surface protein 1; MSP3 $\alpha$ : merozoite surface protein $3 \alpha$. 
ous reports of severe vivax malaria worldwide (Rogerson \& Carter 2008), and the emergence of chloroquine resistance in this species (Baird 2004) are a possible consequences of intra-host competition. The recently increasing tolerance of $P$. vivax hypnozoites to primaquine (Baird \& Rickmann 2003), the only anti-relapse drug currently in clinical use, may have favoured multiple-clone infections in several endemic settings due to superinfection with new strains in patients already carrying relapsing parasites. The available data led Galvani (2003) to suggest that reducing the proportion of multiple-clone infections at the population level could have a major public health impact by decreasing within-host competition and the corresponding selection for increased virulence, transmissibility and/or drug resistance.

Finally, multiple-clone infections may hamper the molecular detection of $P$. vivax relapses in patients continuously exposed to malaria transmission. The distinct ability of $P$. vivax to stay dormant in host liver cells and cause relapses weeks or months after the primary infection complicates the assessment of sequential malaria episodes in observational studies and clinical trials (Baird \& Rieckmann 2003). Until recently, relapses were thought to be caused by hypnozoites that are genetically identical to the blood-stage parasites found in primary infections (Craig \& Kain 1996, Kirchgatter \& del Portillo 1998). This suggested that molecular methods could easily discriminate relapses, which would have the same genotype as the primary infection, from new infections, which would have a different genotype. This view has been challenged by the recent discovery of different parasite genotypes in primary infections and relapses in $72 \%$ of $P$. vivax-infected patients from Thailand, India and Myanmar (Imwong et al. 2007b). Accurate detection of multiple-clone $P$. vivax infections becomes even more important in light of this report. If the primary infection comprises multiple clones, some of them may have been missed, partially characterized or, even worse, had their alleles combined to create artificial haplotypes during genotyping. Likewise, the relapsing clone could have been missed or incorrectly typed during the primary infection, leading to a false conclusion that different genotypes were present during the primary and relapse infections.

\section{Concluding remarks}

Multiple-clone infections with $P$. vivax have been shown to be highly prevalent worldwide, even in areas with relatively low levels of malaria transmission. Limited available data suggests that clonal diversity may be even higher in $P$. vivax than in $P$. falciparum populations co-circulating in the same area. One possible explanation for this is that parasite relapses extend the duration of $P$. vivax carriage and increase the probability that sequential infection with different strains occurs while the relapsing clone is still present.

Experimental rodent malaria models clearly show that the co-existence of two or more genetically distinct clones in the same host increases the rate of evolution of important phenotypes, such as increased virulence, transmissibility and drug resistance, through intra-host competition. Although the evolutionary consequences of multiple-clone $P$. vivax infections remain largely unknown, the recent emergence of more virulent strains and widespread drug resistance suggests that competitive interactions between co-infecting clones may have shaped the recent evolution of this major human malaria parasite. Public health interventions to decrease the prevalence of multiple-clone infections might, therefore, have enormously beneficial consequences.

\section{ACKNOWLEDGEMENTS}

To the Global Health Center (Mount Sinai School of Medicine, New York, NY), for presenting this research opportunity and funding it, and to Dr. Daniel Caplivski, for advice.

\section{REFERENCES}

Anderson TJC, Haubold B, Williams JT, Estrada-Franco JG, Richardson L, Mollinedo R, Bockarie M, Mokili J, Mharakurwa S, French N, Whitworth J, Velez ID, Brockman AH, Nosten F, Ferreira MU, Day KP 2000. Microsatellite markers reveal a spectrum of population structures in the malaria parasite Plasmodium falciparum. Mol Biol Evol 17: 1467-1482.

Anderson TJC, Su XZ, Bockarie M, Lagog M, Day KP 1999. Twelve microsatellite markers for characterization of Plasmodium falciparum from finger-prick blood samples. Parasitology 119: 113-125.

Baird JK 2004. Chloroquine resistance in Plasmodium vivax. Antimicrob Agents Chemother 48: 4075-4083.

Baird JK, Rieckmann KH 2003. Can primaquine therapy for vivax malaria be improved? Trends Parasitol 19: 115-120.

Bell AS, de Roode JC, Sim D, Read AF 2006. Within-host competition in genetically diverse malaria infections: parasite virulence and competitive success. Evolution 60: 1358-1371.

Bonilla JA, Validum L, Cumming R, Palmer CJ 2006. Genetic diversity of Plasmodium vivax Pvesp and Pvmspl in Guyana, South America. Am J Trop Med Hyg 75: 830-835.

Bruce MC, Galinski MR, Barnwell JW, Snounou G, Day KP 1999. Polymorphism at the merozoite surface protein-3 locus of Plasmodium vivax: global and local diversity. Am J Trop Med Hyg 61: $518-525$.

Carlton JM, Adams JH, Silva JC, Bidwell SL, Lorenzi H, Caler E, Crabtree J, Angiuoli SV, Merino EF, Amedeo P, Cheng Q, Coulson RM, Crabb BS, del Portillo HA, Essien K, Feldblyum TV, Fernandez-Becerra C, Gilson PR, Gueye AH, Guo X, Kang'a S, Kooij TW, Korsinczky M, Meyer EV, Nene V, Paulsen I, White O, Ralph SA, Ren Q, Sargeant TJ, Salzberg SL, Stoeckert CJ, Sullivan SA, Yamamoto MM, Hoffman SL, Wortman JR, Gardner MJ, Galinski MR, Barnwell JW, Fraser-Liggett CM 2008. Comparative genomics of the neglected human malaria parasite Plasmodium vivax. Nature 455: 757-763.

Craig AA, Kain KC 1996. Molecular analysis of strains of Plasmodium vivax from paired primary and relapse infections. $J$ Infect Dis 174: 373-379.

Cui L, Escalante AA, Imwong M, Snounou G 2003a. The genetic diversity of Plasmodium vivax populations. Trends Parasitol 19: 220-226.

Cui L, Mascorro CN, Fan Q, Rzomp KA, Khuntirat B, Zhou G, Chen H, Yan G, Sattabongkot J 2003b. Genetic diversity and multiple infections of Plasmodium vivax malaria in Western Thailand. Am J Trop Med Hyg 68: 613-619.

Dean FB, Hosono S, Fang L, Wu X, Farugi AF, Bray-Ward P, Sun Z, Zong Q, Du Y, Du J, Driscoll M, Song W, Kingsmore SF, Egholm 
M, Lasken RS 2002. Comprehensive human genome amplification using multiple displacement amplification. Proc Natl Acad Sci USA 99: 5261-5266.

de Roode JC, Pansini R, Cheesman SJ, Helinski ME, Huijben S, Wargo AR, Bell AS, Chan BH, Walliker D, Read AF 2005. Virulence and competitive ability in genetically diverse malaria infections. Proc Natl Acad Sci USA 102: 7624-7628.

de Valk HA, Meis JFGM, Klaasen CHW 2007. Microsatellite based typing of Aspergillus fumigatus: strengths, pitfalls and solutions. J Microbiol Methods 69: 268-272.

Druilhe P, Daubersies P, Patarapotikul J, Gentil C, Chene L, Chongsuphajaisiddhi T, Mellouk S, Langsley G 1998. A primary malarial infection is composed of a very wide range of genetically diverse but related parasites. J Clin Invest 101: 2008-2016.

Escalante AA, Cornejo OE, Rojas A, Udhayakumar V, Lal AA 2004. Assessing the effect of natural selection in malaria parasites. Trends Parasitol 20: 388-395.

Feng X, Carlton JM, Joy DA, Mu J, Furuya T, Suh BB, Wang Y, Barnwell JW, Su XZ 2003. Single-nucleotide polymorphisms and genome diversity in Plasmodium vivax. Proc Natl Acad Sci USA 100: $8502-8507$.

Ferreira MU, Karunaweera ND, da Silva-Nunes M, Silva NS, Hartl DL, Wirth DF 2007. Population structure and transmission dynamics of Plasmodium vivax in rural Amazonia. J Infect Dis 195: $1218-1226$

Galvani AP 2003. Epidemiology meets evolutionary ecology. Trends Ecol Evol 18: 132-139.

Gomez JC, McNamara T, Bockarie MJ, Baird JK, Carlton JM, Zimmerman PA 2003. Identification of a polymorphic Plasmodium vivax microsatellite marker. Am J Trop Med Hyg 69: 377-389.

Greenhouse B, Myrick A, Dokomajilar C, Woo JM, Carlson EJ, Rosenthal PJ, Dorsey G 2006. Validation of microsatellite markers for use in genotyping polyclonal Plasmodium falciparum infections. Am J Trop Med Hyg 75: 836-842.

Guerra CA, Snow RW, Hay SI 2006. Mapping the global extent of malaria in 2005. Trends Parasitol 22: 353-358.

Gunasekera AM, Wickramarachchi T, Neafsey DE, Ganguli I, Perera L, Premaratne PH, Hartl D, Handunnetti SM, Udagama-Randeniya PV, Wirth DF 2007. Genetic diversity and selection at the Plasmodium vivax apical membrane antigen-1 (PvAMA-1) locus in a Sri Lankan population. Mol Biol Evol 24: 939-947.

Havryliuk T, Orjuela-Sánchez P, Ferreira MU 2008. Plasmodium vivax: microsatellite analysis of multiple-clone infections. Exp Parasitol 120: 330-336.

Hay SI, Guerra CA, Tatem AJ, Noor AM, Snow RW 2004. The global distribution and population at risk of malaria: past, present and future. Lancet Infect Dis 4: 327-336.

Hunter PR, Gaston M 1988. Numerical index of the discriminatory ability of typing systems: an application of Simpson's index of diversity. J Clin Microbiol 26: 2465-2456.

Imwong M, Nair S, Pukrittayakamee S, Sudimack D, Williams JT, Mayxay M, Newton PN, Kim JR, Nandy A, Osorio L, Carlton JM, White NJ, Day NPJ, Anderson TJ 2007a. Contrasting genetic structure in Plasmodium vivax populations from Asia and South America. Int J Parasitol 37: 1013-1022.

Imwong M, Snounou G, Pukrittayakamee S, Tanomsing N, Kim JR, Nandy A, Guthmann JP, Nosten F, Carlton J, Looareesuwan S, Nair S, Sudimack D, Day NP, Anderson TJ, White NJ 2007b. Relapses of Plasmodium vivax infection usually result from activation of heterologous hypnozoites. J Infect Dis 195: 927-933.
Imwong M, Sudimack D, Pukrittayakamee S, Osório L, Carlton JM, Day NPJ, White NJ, Anderson TJC 2006. Microsatellite variation, repeat array length and population history of Plasmodium vivax. Mol Biol Evol 23: 1016-1018.

Joshi H, Prajapati SK, Verma A, Kang'a S, Carlton JM 2008. Plasmodium vivax in India. Trends Parasitol 24: 228-235.

Joshi H, Subbarao SK, Raghavendra K, Sharma VP 1989. Plasmodium vivax: enzyme polymorphism in isolates of Indian origin. Trans R Soc Trop Med Hyg 83: 179-181.

Joy D, Mu J, Su X 2004. Microsatellite markers and population genetics in Plasmodium falciparum. In AP Waters, Jense CJ, Malaria parasites: genomes and molecular biology, Caister Academic Press, Wymondham, p. 177-186.

Joy DA, Gonzalez-Ceron L, Carlton JM, Gueye A, Fay M, McCutchan TF, Su XZ 2008. Local adaptation and vector-mediated population structure in Plasmodium vivax malaria. Mol Biol Evol 25: $1245-1252$.

Karunaweera ND, Ferreira MU, Hartl DL, Wirth DF 2007. Fourteen polymorphic microsatellite DNA markers for the human malaria parasite Plasmodium vivax. Mol Ecol Notes 7: 172-175.

Karunaweera ND, Ferreira MU, Munasinghe A, Barnwell JW, Collins WE, King CL, Kawamoto F, Hartl DL, Wirth DF 2008. Extensive microsatellite diversity in the human malaria parasite Plasmodium vivax. Gene 410: 105-112.

Kim JR, Imwong M, Nandy A, Chotivanich K, Nontprasert A, Tonomsing N, Maji A, Addy M, Day NPJ, White NJ, Pukrittayakamee S 2006. Genetic diversity of Plasmodium vivax in Kolkata, India. Malaria J 5: 71.

Kimura E, Mattei D, di Santi SM, Scherf A 1990. Genetic diversity in the major merozoite surface antigen of Plasmodium falciparum: high prevalence of a third polymorphic form detected in strains derived from malaria patients. Gene 91: 57-62.

Kirchgatter K, del Portillo HA 1998. Molecular analysis of Plasmodium vivax relapses using the $M S P 1$ molecule as a genetic marker. J Infect Dis 177: 511-515.

Kolakovich KA, Ssengoba A, Wojcik K, Tsuboi T, Al-Yaman F, Alpers M, Adams JH 1996. Plasmodium vivax: favored gene frequencies of the merozoite surface protein-1 and the multiplicity of infection in a malaria endemic region. Exp Parasitol 83: 11-18.

Leclerc MC, Durant P, Gauthier C, Patot S, Billote N, Menegon M, Severini C, Ayala FJ, Renaud F 2004. Meager genetic variability of the human malaria agent Plasmodium vivax. Proc Natl Acad Sci USA 101: 14455-14460.

Mackinnon MJ, Read AF 2004. Virulence in malaria: an evolutionary viewpoint. Phil Trans $R$ Soc Lond B 359: 965-986.

Porto M, Ferreira MU, Camargo LM, Premawansa S, del Portillo HA 1992. Second form in a segment of the merozoite surface protein 1 gene of Plasmodium vivax among isolates from Rondonia (Brazil). Mol Biochem Parasitol 54: 121-124.

Prajapati SK, Verma A, Adak T, Yadav RS, Kumar A, Eapen A, Das MK, Singh N, Sharma SK, Rizvi MA, Dash AP, Joshi H 2006. Allelic dimorphism of Plasmodium vivax gam-1 in the Indian subcontinent. Malaria J 5: 90.

Price RN, Tjitra E, Guerra CA, Yeung S, White NJ, Anstey NM 2007. Vivax malaria: neglected and not benign. Am J Trop Med Hyg 77: $79-87$.

Rogerson SJ, Carter R 2008. Severe vivax malaria: newly recognized or rediscovered? PLoS Med 5: e136.

Rosario V 1981. Cloning of naturally occurring mixed infections of malaria parasites. Science 212: 1037-1038. 
Sattabongkot J, Tsuboi T, Zollner GE, Sirichaisinthop J, Cui L 2004. Plasmodium vivax transmission: chances for control? Trends Parasitol 20: 192-198.

Schlotterer C 1998. Microsatellite DNA. In AR Hoezel, Molecular genetic analysis of populations: a practical approach, 2nd ed., IRL Press, Oxford, p. 237-261.

Taylor LH, Walliker D, Read AF 1997. Mixed-genotype infections of the rodent malaria Plasmodium chabaudi are more infectious to mosquitoes than single-genotype infections. Parasitology 115: 121-132.

Udagama PV, David PH, Peiris JSM, Ariyaratne YG, Perera KLRL, Mendis KN 1987. Demonstration of antigenic polymorphism in Plasmodium vivax malaria with a panel of 30 monoclonal antibodies. Infect Immun 55: 2604-2611.
Udagama PV, Gamage-Mendis AC, David PH, Peiris JS, Perera KLRL, Carter R 1990. Genetic complexity of Plasmodium vivax parasites in individual human infections analyzed with monoclonal antibodies against variant epitopes on a single parasite protein. Am J Trop Med Hyg 42: 101-110.

Udomsangpetch R, Kaneko O, Chotivanich K, Sattabongkot J 2008. Cultivation of Plasmodium vivax. Trends Parasitol 24: 85-88.

Wang Y, Nair S, Nosten F, Anderson T 2008. Multiple displacement amplification for malaria parasite DNA. J Parasitol 5: 1. [Epub ahead of print].

Wargo AR, Huijben S, de Roode JC, Shepherd J, Read AF 2007. Competitive release and facilitation of drug-resistant parasites after therapeutic chemotherapy in a rodent malaria model. Proc Natl Acad Sci USA 104: 19914-19919. 